Original Research Paper

\title{
Adsorption and Descaling of Cellucotton and Chitosan- Modified Bentonite for Produced Water
}

\author{
${ }^{1,2}$ Tao Yu, ${ }^{1,2}$ Ying Wang, ${ }^{1,2,3 *}$ Chengtun Qu, ${ }^{1,2}$ Jinling Li and ${ }^{1,2}$ Bo Yang \\ ${ }^{1}$ School of Chemistry and Chemical Engineering, Xi'an Shiyou University, Xi'an 710065, China \\ ${ }^{2}$ Shaanxi Key Laboratory of Environmental Pollution Control Technology and Reservoir Protection of OilField, \\ Xi'an Shiyou University, Xi'an 710065, China \\ ${ }^{3}$ State Key Laboratory of Petroleum Pollution Control \\ CNPC Research Institute of Safety and Environmental Technology, Beijing 102206, China
}

\author{
Article history \\ Received: 10-03-2020 \\ Revised: 22-04-2020 \\ Accepted: 12-05-2020 \\ Corresponding Author: \\ Chengtun $\mathrm{Qu}$ \\ School of Chemistry and \\ Chemical Engineering, Xi'an \\ Shiyou University, Xi'an \\ 710065, China \\ Email: xianquct@yeah.net
}

\begin{abstract}
The compatibility of non-identical layers within the water present in the produced oil is poor and ion reactions in the oil mixed with water result in scale formation, thereby having a significant impact on oilfield safety production. In this study, methods for the descaling of produced water from different blocks were studied according to the quality characteristics of the produced water. Results show that scale was produced at a concentration of $94 \mathrm{mg} / \mathrm{L}$ when three-phase separated water and formation water were mixed at a volume ratio of 1:0.3. The flocculation performance was optimized when the $\mathrm{pH}$ of the mixed water sample was adjusted to 7.5 and addition amount of polyaluminium chloride and polyacrylamide was 80 and $3 \mathrm{mg} / \mathrm{L}$, respectively. In addition, the mixed water sample was adsorbed and descaled using cellucotton and chitosanmodified bentonite. Results show that the method for treating the mixed water sample first with cellucotton followed by the chitosan-modified bentonite shows the optimal adsorption-flocculation performance, thereby reducing the concentration of scale in the treated water to $3 \mathrm{mg} / \mathrm{L}$.
\end{abstract}

Keywords: Produced Water, Adsorption, Descaling, Chitosan-Modified Bentonite

\section{Introduction}

At present, majority of oilfields in China have entered the middle and late exploitation stages, the water content in the produced oil is continuously increasing (and is $>80 \%$ in some cases) and the output of oil mixed with water is increasing. Yuan and Wang (2018; Chen et al., 2018) If produced water is discharged directly without reasonable and effective treatment, it will lead deteriorate the surrounding environment and pollute the groundwater resources. Song et al. (2013; Yang et al., 2006) Therefore, the treatment and reinjection of the sewage can meet the production needs of oilfields, conserve considerable water resources and bring certain economic benefits. Yin et al. (2018; Wang et al., 2019a)

There are great differences in the properties of produced water in different areas; however, they all have the characteristics of high oil content, high salinity and complex water quality. Li et al. (2019; Wang et al., 2019b) These characteristics lead to difficulties in the treatment and reinjection of produced water in the later stage. Wu et al. (2010; Liu et al., 2019) At present, the reinjection of produced water from a single block can no longer satisfy the needs of oilfield production. Owing to the development in oilfield production technology, mixed production and injection have become an important technology to enhance oil recovery and fully utilize produced water in oilfields. Tong et al. (2015) However, the properties of produced water from different blocks and ion concentrations in the water differ, which lead to the phenomenon of incompatibility after mixing two water types and producing large amounts of scale which block pipelines and affect water injection in the later stage. (Amiri et al., 2012; Amiri and Moghadasi, 2013).

High ion content and incompatibility of mixed water layers in the production wastewater are the internal causes of scaling, whereas water temperature, $\mathrm{pH}$, pressure and salt content are external causes (Helton et al., 2017; Polat et al., 2017). Therefore, scaling control technologies for production wastewater mainly include the following: Reducing the content of scale-forming ions (e.g., the softening method); avoiding incompatibility with water mixing; controlling 
exogenous conditions (e.g., adjusting $\mathrm{pH}$ ); and adding scale inhibitor, which is the main method for oilfield scale control (Al-Khaldi et al., 2011; Shukla et al., 2018) that destroys the process of scale crystal formation.

Herein, two kinds of easy-to-scale waters with different properties were premixed to enable the scaling ions in the water to react and scale in advance. The scaling substances in the water were removed through later adsorption-flocculation, which could avoid the meeting and scaling of the later-produced water in the oil layer and impacts on the subsequent exploitation. Using the high-scale mixing proportion of authentic oilfield produced water (wastewater), this study explored changes in the flocculation reagent system, i.e., $\mathrm{pH}$, Polyaluminum Chloride (PAC) and Polyacrylamide (PAM) and adsorption agent system, i.e., chitosan-modified clay and cellucotton, to determine the effects on the properties of mixed water scaling. By comparing different combinations of descaling effects on the control of fouling within the mixed water, it was found that "cellucotton plus chitosan-modified clay" secondary adsorption and flocculation precipitation could be combined to form a hybrid high-scale adsorption descaling technology for produced water.

\section{Materials and Methods}

\section{Reagents and Instruments}

The experimental reagents were ammonium chloride, liquid ammonia, eriochrome black $\mathrm{T}$, hydroxylamine hydrochloride, anhydrous ethanol, sodium hydroxide, zinc oxide, barium chloride, sodium hexametaphosphate and anhydrous sodium carbonate, which are all analytically pure; Polyaluminium Chloride (PAC), Polyacrylamide (PAM), chitosan-modified bentonite (homemade, Yu et al., 2018) and cellucotton.

Experimental instruments were a constant temperature oscillating incubator (TS-200B), vacuum pump (SHB-III), electronic analytical balance (CP114) and an electrothermal constant temperature drying oven (101 Type).

\section{Experimental Methods}

\section{Water Quality Analysis}

Water samples were analyzed according to Oilfield Water Analysis Method (SY/T5523-2006) and Recommended Indexes and Analysis methods of Water Injection Quality in Clastic Reservoirs (SY/T5329-2012).

\section{Adsorption and Descaling}

(1) The three-phase separated water and formation water were mixed according to the volume ratio of 1:0.3 and then the cellucotton was added followed by adsorption in the oscillating incubator at $40^{\circ} \mathrm{C}$ for 2 days. After removing the cellucotton, the flocculation sedimentation experiment on the mixed water sample was conducted and adsorption effect was investigated based on the ion concentration in the treated water

(2) After mixing the three-phase separated water and formation water at a volume ratio of 1:0.3, a certain amount of chitosan-modified bentonite was added followed by adsorption at $40^{\circ} \mathrm{C}$ for a certain time. The flocculation sedimentation experiment of the mixed water sample was conducted and adsorption effect was investigated based on the ion concentrations in the treated water

\section{Determination of Scale Amount}

Treated water was filtered through a $0.45-\mu \mathrm{m}$ filter membrane by suction and maintained at $40^{\circ} \mathrm{C}$ for 3 days. The weight change before and after the treatment was measured to determine the amount of scale in the treated water.

\section{Determination of Light Transmittance}

Ultraviolet spectrophotometer (UV-2350) was used to determine the light transmittance of produced water before and after flocculation at $420 \mathrm{~nm}$.

\section{Results and Discussion}

Water Quality Analysis and Compatibility Analysis of Formation Water and Three-Phase Separated Water

To ensure accurate treatment and reinjection of the produced water from oilfields, it is necessary to analyze the quality of the reinjected water. The results of water quality analyses of formation water and three-phase separated water are shown in Table 1.

The formation water belonged to the typical $\mathrm{Na}_{2} \mathrm{SO}_{4}$ type and the $\mathrm{SO}_{4}{ }^{2-}$ anion concentration was 2313.02 $\mathrm{mg} / \mathrm{L}$; the three-phase separated water was $\mathrm{CaCl}_{2}$-type water and the $\mathrm{Ca}^{2+}$ concentration was $2462.92 \mathrm{mg} / \mathrm{L}$. If the two water types are mixed, the scaling phenomenon is very likely to appear and if they are reinjected directly without treatment, serious blockage of the pipeline and even blockage of the stratum will be caused, resulting in an impact on the effect of water injection in the later stage. Forming precipitation will be easy to scale in the form of the following reaction:

$$
\mathrm{Ca}^{2+}+\mathrm{SO}_{4}^{2-} \rightarrow \mathrm{CaSO}_{4} \downarrow
$$

As shown in Fig. 1, the concentrations of calcium ions $\left(\mathrm{Ca}^{2+}\right)$ and sulfate ions $\left(\mathrm{SO}_{4}{ }^{2-}\right)$ and total hardness in the mixed water samples exhibited obvious downward trends after $8 \mathrm{~h}$ mixing, indicating that the ions in the water reacted with each other to form $\mathrm{CaSO}_{4}$ scale. 


\section{Optimization of Coagulation Experiment Conditions}

\section{Optimization of $\mathrm{pH}$}

The $\mathrm{pH}$ value of the mixed water was adjusted after mixing the three-phase separated water and formation water according to the volume ratio of 1:0.3. Then, 100 and $1 \mathrm{mg} / \mathrm{L}$ of PAC and PAM, respectively, were added to flocculate the mixed water sample. The optimized $\mathrm{pH}$ value was selected by taking the light transmittance as the index. The results are shown in Fig. 2.

With the increased $\mathrm{pH}$ value, the light transmittance of the supernatant initially decreased and then increased. The light transmittance was approximately $82 \%$ and $90 \%$ at $\mathrm{pH}$ 7.5 and 9 , respectively. However, white precipitates were produced after a certain time period (Fig. 2) as the $\mathrm{pH}$ value increased; these may have been formed because the $\mathrm{Ca}$ and
$\mathrm{Mg}$ ions in water were under alkaline conditions. Furthermore, a large amount of sludge was produced in the flocculation treatment (Fig. 3), which resulted in difficulties for the follow-up treatment. Therefore, a $\mathrm{pH}$ value of 7.5 was adopted for the flocculation experiment after comprehensive consideration.

\section{Optimization of the Addition Amount of PAC}

The three-phase separated water and formation water were mixed according to the volume ratio of 1:0.3 and then the $\mathrm{pH}$ was adjusted to 7.5. Different amounts of PAC and $1 \mathrm{mg} / \mathrm{L}$ of PAM were added in the mixed water solution for flocculation treatment and the optimal addition amount of PAC was selected by taking the light transmittance as the evaluation index. The results are shown in Fig. 3.

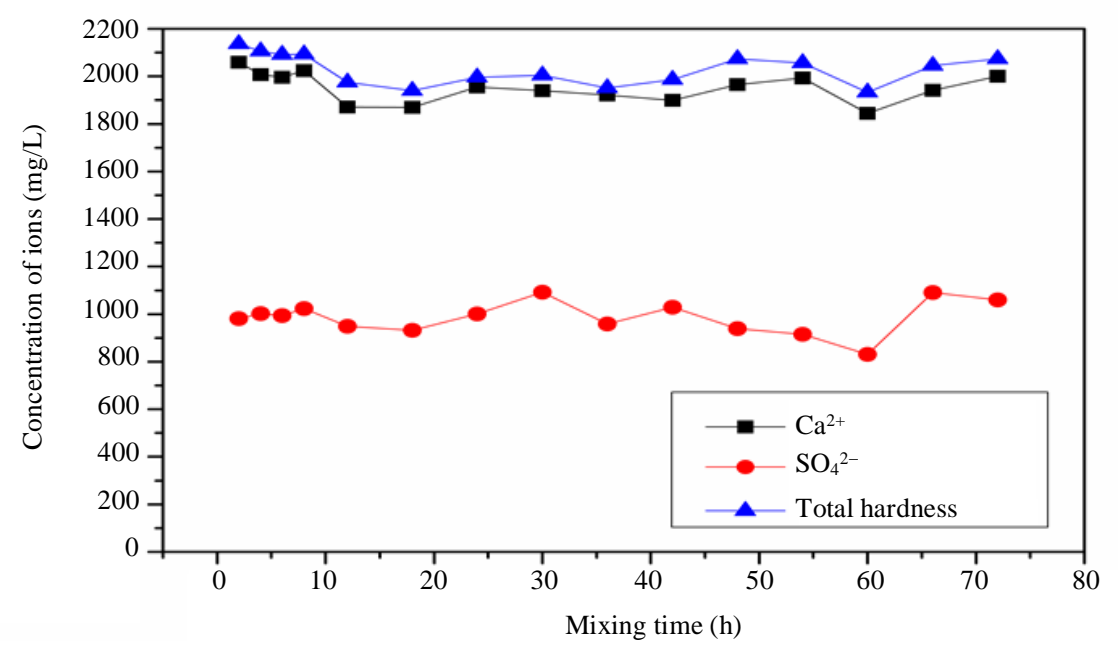

Fig. 1: Concentration of ions in the mixed water sample at different time points

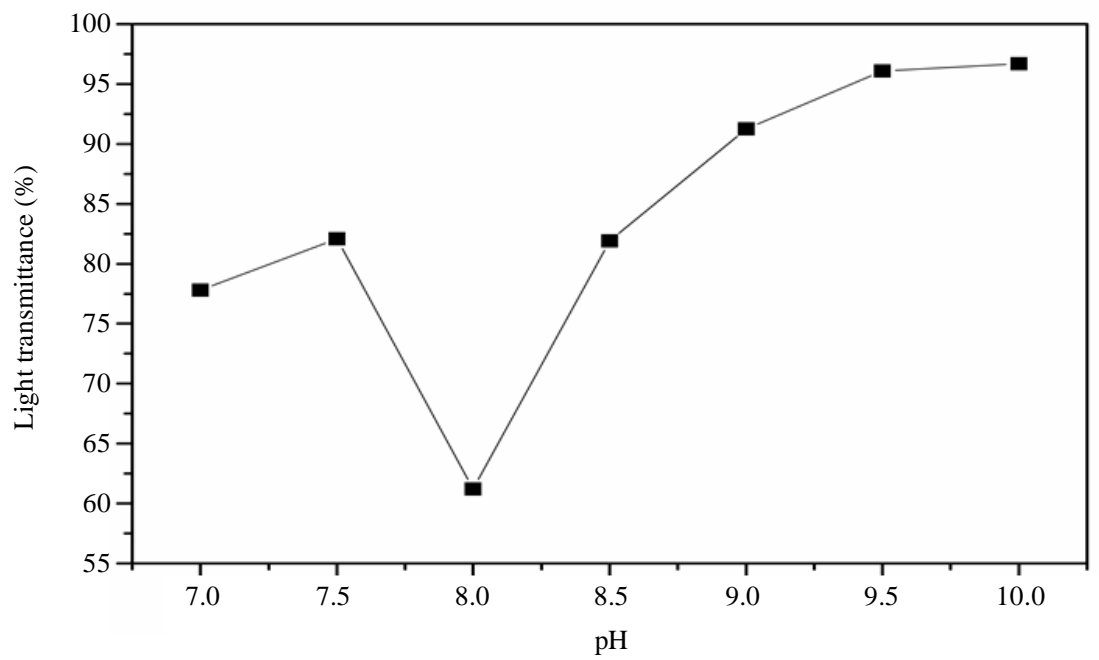

Fig. 2: Light transmittance of mixed water supernatant after treatments at different $\mathrm{pH}$ values 


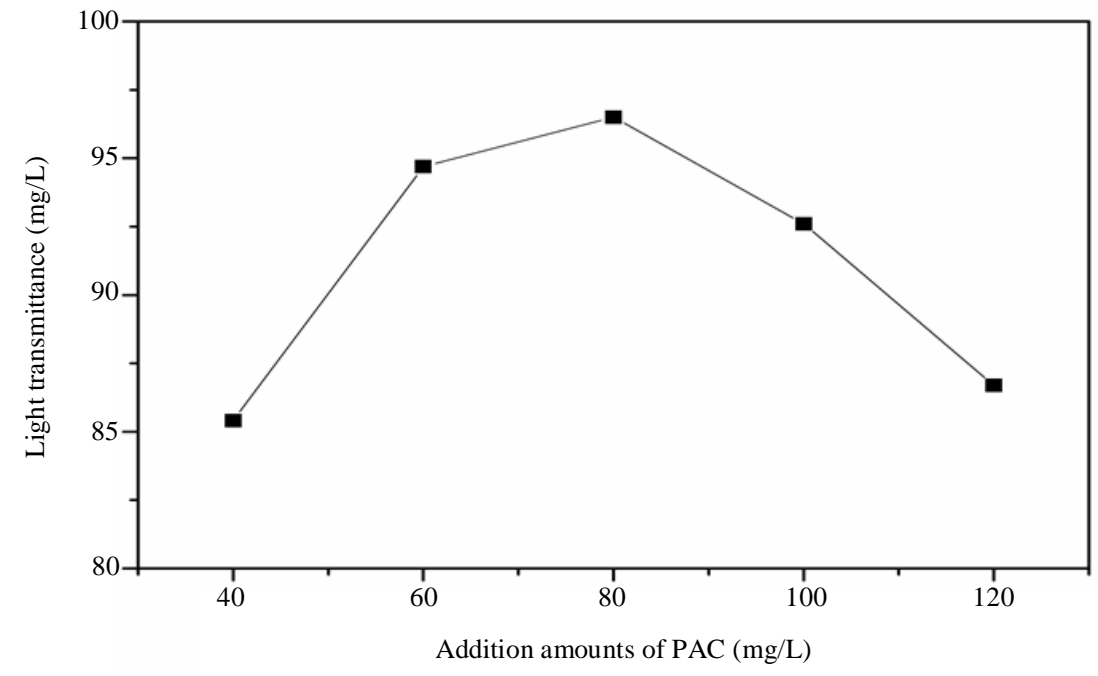

Fig. 3: Effect of different addition amounts of PAC on light transmittance of mixed water supernatant after flocculation treatment

Table 1: Water quality of formation water and three-phase separated water

\begin{tabular}{|c|c|c|c|c|c|c|c|c|c|}
\hline \multirow[b]{2}{*}{ Sample } & \multirow{2}{*}{$\begin{array}{l}\text { Salinity } \\
/ \mathrm{mg} \cdot \mathrm{L}^{-1}\end{array}$} & \multicolumn{8}{|c|}{ Major scaling ions $/ \mathrm{mg} \cdot \mathrm{L}^{-1}$} \\
\hline & & $\mathrm{Ca}^{2+}$ & $\mathrm{Mg}^{2+}$ & $\mathrm{Cl}^{-}$ & $\mathrm{CO}_{3}{ }^{2-}$ & $\mathrm{HCO}_{3}^{-}$ & $\mathrm{SO}_{4}^{2-}$ & $\mathrm{pH}$ & Water type \\
\hline Formation water & 5210.83 & 540.08 & 199.95 & 1146.64 & 0 & 119.29 & 2313.02 & 6.5 & $\mathrm{Na}_{2} \mathrm{SO}_{4}$ \\
\hline Three-phase separated water & 25388.24 & 2462.92 & 102.10 & 14870.39 & 0 & 198.01 & 726.01 & 6.5 & $\mathrm{CaCl}_{2}$ \\
\hline
\end{tabular}

As shown in Fig. 3, the light transmittance of supernatant first increased and then decreased with increasing PAC. The treatment effect was optimal when the addition amount of PAC is $80 \mathrm{mg} / \mathrm{L}$, with the light transmittance of the supernatant reaching $96.8 \%$. Therefore, the optimal amount of flocculant of $80 \mathrm{mg} / \mathrm{L}$ was used in the later flocculation experiment.

\section{Optimization of the Addition Amount of PAM}

The three-phase separated water and formation water were mixed according to the volume ratio of 1:0.3 and then the $\mathrm{pH}$ was adjusted to 7.5 , followed by the addition of $80 \mathrm{mg} / \mathrm{L}$ of PAC and different amounts of PAM for the flocculation treatment. The optimal addition amount of PAM was selected by considering the light transmittance as the evaluation index. The results are shown in Fig. 4.

Figure 4 shows that with the increase of the addition amount of PAM, the light transmittance of the supernatant after treatment first increased and then decreased. When the addition amount of PAM was 3-5 $\mathrm{mg} / \mathrm{L}$, the light transmittances of the supernatants were > $98 \%$. Therefore, the addition amount of PAM herein was optimized to be $3 \mathrm{mg} / \mathrm{L}$ by considering economic benefits. In conclusion, the optimized experimental conditions for flocculation experiments are as follows: $\mathrm{pH}$ Value of 7.5, addition amount of PAC and PAM of 80 and $3 \mathrm{mg} / \mathrm{L}$, respectively.
Experiment on Adsorption and Descaling of Chitosan-Modified Bentonite

\section{Effect of Adsorption Time on Scale Removal}

After the two water types were mixed according to a volume ratio of 1:0.3, $400 \mathrm{mg} / \mathrm{L}$ of modified clay was added to the mixture; this was followed by the adsorption experiment at $40^{\circ} \mathrm{C}$ for a certain time period. Then, the flocculation sedimentation experiment of the mixed water sample was conducted and the adsorption performance was evaluated by the ion concentration in the treated water.

The surface of chitosan-modified clay particles features both hydroxyl and carboxyl groups, which can absorb the scale crystals and induce accumulation on the surface. Then, the scale crystals can be precipitated by flocculation to remove scale crystals from water (Yu et al., 2018).

As shown in Fig. 5, after treating the mixed water samples with adsorption-flocculation using chitosanmodified bentonite, the concentrations of the scaling ions in the water changed with the increase of adsorption time and the $\mathrm{SO}_{4}{ }^{2-}$ concentration first decreased and then increased. The changing trends in the calcium and magnesium ion concentrations in water were not significant, while the scale of water samples treated by adsorption materials decreased obviously. After $20 \mathrm{~min}$ of adsorption, the $\mathrm{SO}_{4}{ }^{2-}$ ion concentration decreased to its lowest value, indicating that the chitosan-modified bentonite has the largest adsorption capacity of scaling 
ions in water. Therefore, $20 \mathrm{~min}$ was determined as the optimal adsorption time herein.

\section{Descaling Performance of Chitosan-Modified Bentonite}

After mixing the two water types according to the volume ratio of 1:0.3, different amounts of chitosanmodified bentonite were added followed by adsorption for $20 \mathrm{~min}$ at $40^{\circ} \mathrm{C}$. The flocculation sedimentation experiment on the mixed water sample was then carried out and the adsorption performance was evaluated based on the concentrations of ions in the treated water. The experiment results are shown in Fig. 6.
The scaling ions in the mixed water samples decreased significantly after the addition of different amounts of modified bentonite for the adsorption-flocculation treatment. When the addition amount of modified bentonite was $500 \mathrm{mg} / \mathrm{L}$, the $\mathrm{SO}_{4}{ }^{2-}$ concentration decreased from 1052.80 to $810.79 \mathrm{mg} / \mathrm{L}$. Besides, with an increase in the amount of added modified bentonite, the scale amount in the water treated by adsorption-flocculation also decreased (to $24 \mathrm{mg} / \mathrm{L}$ ), while the scale amount in water treated by direct flocculation was $94 \mathrm{mg} / \mathrm{L}$, showing that the scale amount was significantly lower after the adsorptionflocculation treatment. Therefore, the addition of modified clay was optimized to be $500 \mathrm{mg} / \mathrm{L}$ herein.

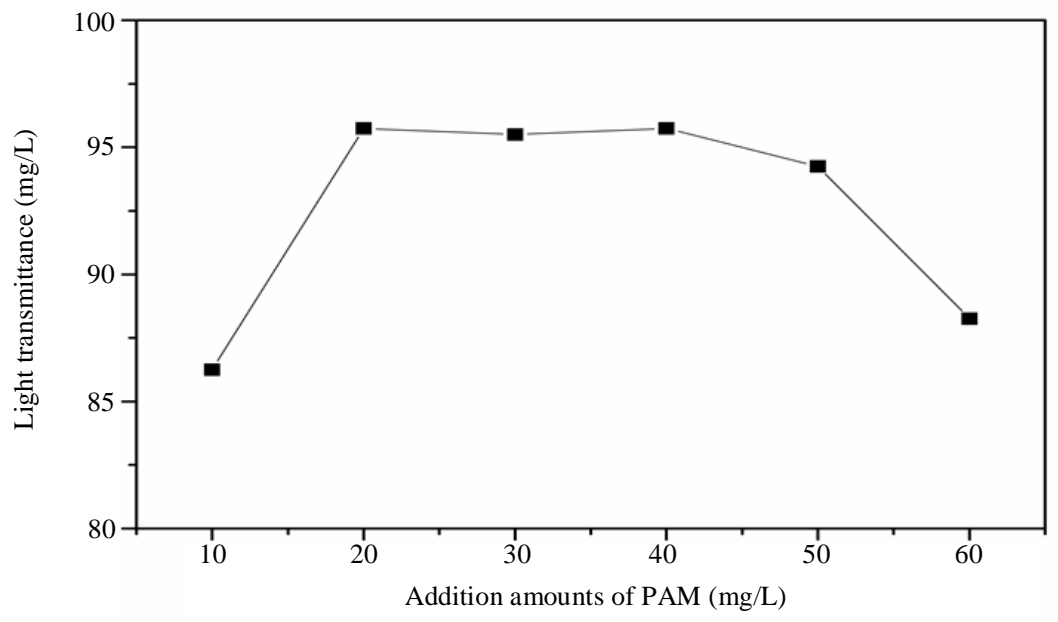

Fig. 4: Effect of different addition amounts of PAM on light transmittance of mixed water supernatant after flocculation treatment

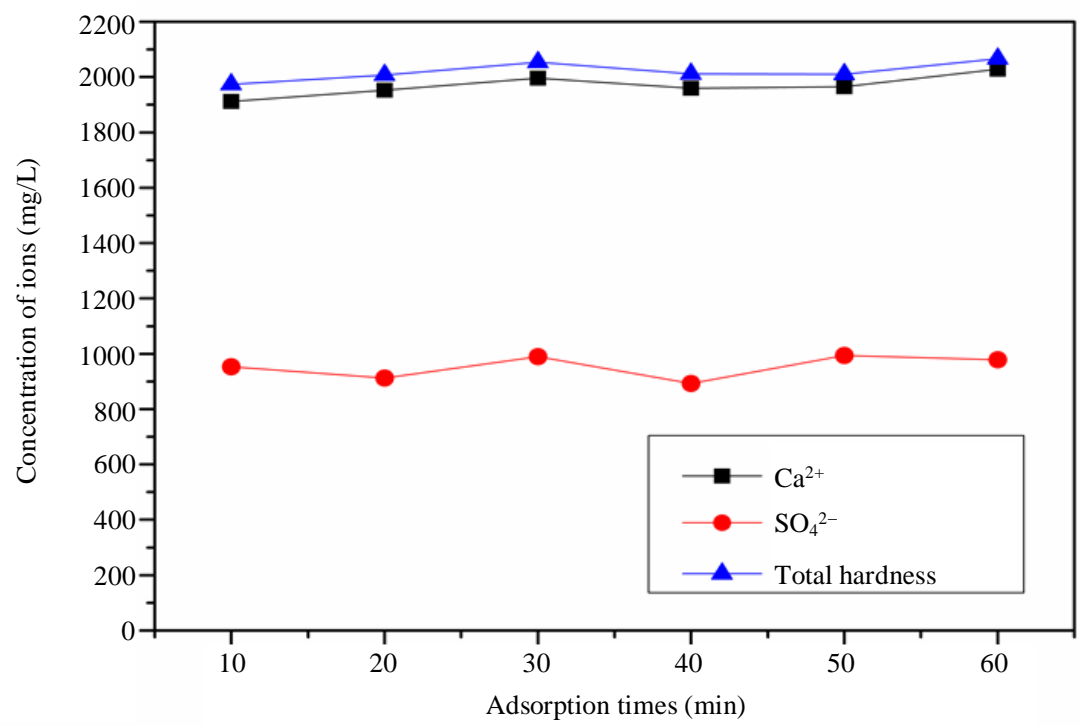

Fig. 5: Changes in ion concentrations in water samples treated with adsorption-flocculation using chitosan-modified bentonite at different adsorption times 


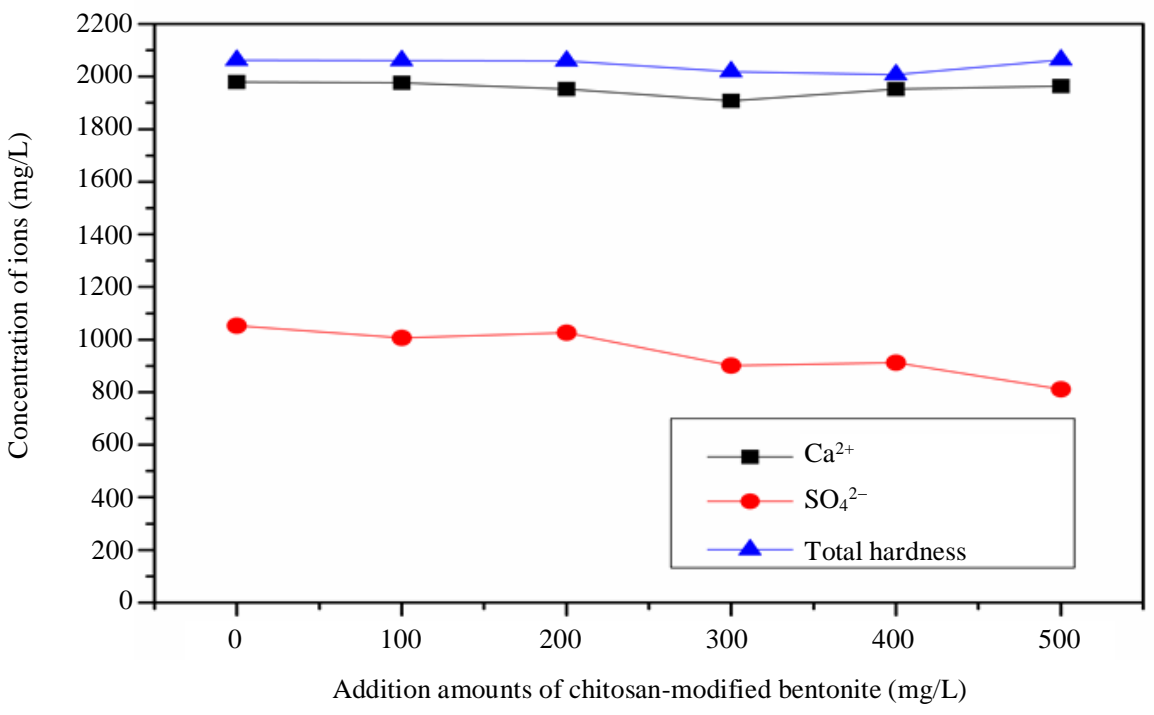

Fig. 6: Changes in ion concentrations in water samples after adsorption and flocculation using different amounts of chitosanmodified bentonite

Table 2: Changes in ion concentrations in water samples after cellucotton adsorption

\begin{tabular}{lllll}
\hline Treatment & $\mathrm{Ca}^{2+}(\mathrm{mg} / \mathrm{L})$ & Total hardness $(\mathrm{mg} / \mathrm{L})$ & $\mathrm{SO}_{4}{ }^{2-}(\mathrm{mg} / \mathrm{L})$ & Scale amount $(\mathrm{mg} / \mathrm{L})$ \\
\hline Flocculation & 1843.68 & 1940.92 & 1021.52 & 94 \\
Adsorption-flocculation & 1823.64 & 1911.15 & 983.65 & 17 \\
\hline
\end{tabular}

Table 3: Changes in ion concentrations in water samples after adsorption and flocculation of cellucotton and chitosan-modified bentonite

\begin{tabular}{lllll}
\hline Methods of adding chitosan-modified bentonite & $\mathrm{Ca}^{2+}(\mathrm{mg} / \mathrm{L})$ & Total hardness $(\mathrm{mg} / \mathrm{L})$ & $\mathrm{SO}_{4}{ }^{2-}(\mathrm{mg} / \mathrm{L})$ & Scale concentration $(\mathrm{mg} / \mathrm{L})$ \\
\hline- & 1887.77 & 1997.16 & 1086.54 & 17 \\
Directly adding chitosan-modified bentonite & 1973.94 & 2043.22 & 1043.74 & 7 \\
Adding suspension & 1777.55 & 1848.04 & 940.85 & 3 \\
\hline
\end{tabular}

\section{Adsorption and Descaling Performance of Cellucotton}

After the two water types were mixed according to the volume ratio of $1: 0.3$, the scaling ions in water were treated by cellucotton for adsorption. The results are shown in Table 2.

As shown in Table 2, the concentration of scaling ions in the water decreased after adsorption-flocculation treatment, indicating that the addition of cellucotton had a certain effect on the adsorption of scaling ions in the mixed water. The amount of scale in the treated water was also determined; after adsorption-flocculation treatment it decreased to $17 \mathrm{mg} / \mathrm{L}$, thereby indicating that the descaling performance of cellucotton was superior to that of chitosan-modified bentonite.

\section{Coadsorption Descaling Performance of Cellucotton and Chitosan-Modified Bentonite}

Through the above experiments it was found that the amount of scale in the water sample treated with cellucotton for adsorption was obviously smaller. The mixed water sample was treated with these two adsorption materials for adsorption-flocculation to achieve coadsorption descaling and achieve an overall improved descaling performance. The results are shown in Table 3.

Table 3 shows that after initially descaling by treating the mixed water sample with cellucotton, 500 $\mathrm{mg} / \mathrm{L}$ of chitosan-modified bentonite was then added to further reduce the amount of scale in the mixed water sample. After coadsorption and descaling by the two materials, the amount of scale in the mixed water sample was obviously reduced. In addition, when the chitosan-modified bentonite suspension was added in the mixed water, the descaling performance was further enhanced, achieving a scale concentration of only $3 \mathrm{mg} / \mathrm{L}$ in the treated water. After coadsorptionflocculation treatment, the scaling ion concentrations were also decreased, indicating that cellucotton and chitosan-modified bentonite can effectively absorb scaling ions and achieve the effect of scale removal. (Nan et al., 2015) 


\section{Conclusion}

Based on the above research, the mixed high-scaling produced water adsorption and descaling technology of the combination of fiber cotton and chitosan modified clay with secondary adsorption and flocculation was proposed for the first time. The main conclusions include the following:

(1) Analysis of water quality shows that the three-phase separated water belonged to $\mathrm{CaCl}_{2}$-type water and the formation water belonged to $\mathrm{Na}_{2} \mathrm{SO}_{4}$-type water. When these were mixed at a volume ratio of 1:0.3, $\mathrm{CaSO}_{4}$ scale was produced at the highest concentration of $94 \mathrm{mg} / \mathrm{L}$

(2) Optimal conditions of coagulation treatment are as follows: $\mathrm{pH}$ Value of 7.5 and addition of 80 and 3 $\mathrm{mg} / \mathrm{L}$ of PAC and PAM, respectively

(3) The mixed water sample was adsorbed and descaled by cellucotton and chitosan-modified bentonite, showing that cellucotton has a better descaling performance with a scale concentration of $17 \mathrm{mg} / \mathrm{L}$ in the water sample following the adsorptionflocculation treatment

(4) Scale was removed by coadsorption-flocculation with cellucotton and chitosan-modified bentonite. The optimal performance was achieved when scale was first treated with cellucotton, followed by a 500 $\mathrm{mg} / \mathrm{L}$ suspension of chitosan-modified bentonite for adsorption; the result was a scale concentration of 3 $\mathrm{mg} / \mathrm{L}$ in the treated water

\section{Acknowledgment}

This work was supported by the National Natural Science Foundation of China (Grant No.21376189) and Special Scientific Research Project Foundation of the Science and Technology Department of Shaanxi Province (Grant No.14JS087).

\section{Author's Contributions}

Tao Yu: Writing the article, research concept and design.

Ying Wang: Research concept and design.

Chengtun Qu: Collect and/or assembly of data.

Jinling Li: Critical revision of the article.

Bo Yang: Final approval of article.

\section{Ethics}

This article is original and contains unpublished material. The corresponding author confirms that all of the other authors have read and approved the manuscript and no ethical issues involved.

\section{References}

Al-Khaldi, M.H., A.M. Al-Juhani, S.H. Al-Mutairi and M.N. Gurmen, 2011. New insights into the removal of calcium sulfate scale. Proceedings of the Society of Petroleum Engineers 9th European Formation Damage Conference, Jun. 7-10, Noordwijk, The Netherlands, pp: 1052-1070. DOI: $10.2118 / 144158-M S$

Amiri, M. and J. Moghadasi, 2013. The effect of temperature, pressure and mixing ratio of injection water with formation water on barium sulfate scale formation in Siri oilfield. Energy Sources, Part A: Recovery Utilization Environ. Effec., 35: 1316-1327. DOI: $10.1080 / 15567036.2010 .516322$

Amiri, M., J. Moghadasi and M. Pordel, 2012. The effect of temperature, pressure and mixing ratio of the injection water with formation water on strontium sulfate scale formation in the Siri oilfield. Petroleum Sci. Technol., 30: 635-645.

DOI: $10.1080 / 10916466.2010 .489088$

Chen, M.F., J.H. Shi, X.Q. Zhu and A.Q. Huang, 2018. Joint development and production replacement for development optimization of multiple oilfields in Deepwater oil region. Oil Gas Geol., 39: 620-630. DOI: $10.11743 / \operatorname{ogg} 20180320$

Helton, A.M., R.O. Hall and T.J. Battin, 2017. Scaling of dissolved organic carbon removal in river networks. Adv. Water Res., 110: 136-146. DOI: 10.1016/j.advwatres.2017.10.009

Li, J., Y.R. Wang, S.L. Li, L.P. Fang and G.C. Hou et al., 2019. Water quality deterioration of treated oilfield injection water in the water distribution system of the Jianghan oilfield. Water Sci. Technol. Water Supply, 19: 519-526. DOI: $10.2166 /$ ws.2018.097

Liu, X.L., J.S. Liu, W.Y. Li and X. Jiang, 2019. Effect of injection salinity and water head on brine aquifer permeability. Taiyangneng Xuebao/Acta Energiae Solaris Sinica, 40: 447-455.

Madhusudhana, R.P., C.J. Chang, J.K. Chen, C.F. Huang and C.Y. Chou et al., 2019. Polymer-coated gauze as efficient, reusable and economically viable adsorbents for the removal of $\mathrm{Ni}^{2+}$ ion. Reactive Funct. Polymers, 134: 1-9. DOI: 10.1016/j.reactfunctpolym

Mahmoud, M.A., 2014. Evaluating the damage caused by calcium sulfate scale precipitation during lowand high-salinity-water injection. J. Canadian Petroleum Technol., 53: 141-150.

DOI: $10.2118 / 164634-P A$

Nan, H., C. Wang, G. Wang, H. Lin and H.M. Wei et al., 2015. Scale preparation of carbon nanotubes/epoxy resin cellucotton composite and its oil/water separation performance. Huagong Xuebao/CIESC J., 66: 1194-1200. DOI: 10.11949/j.issn.0438-1157.20141432 
Polat, S., P. Sayan and S.T. Sargut, 2017. Investigation of calcium sulfate dihydrate crystallization in the presence of glutamic acid in MSMPR crystallizer. J. Faculty Eng. Archit. Gazi Univ., 32: 1121-1130. DOI: 10.17341/gazimmfd.369501

Song, Z.J., Z.P. Li, F.P. Lai, G. Liu and H.H. Gan, 2013. Derivation of water flooding characteristic curve for high water-cut oilfields. Shiyou Kantan Yu Kaifa/Petroleum Exp. Dev., 40: 201-208. DOI: 10.11698/PED.2013.02.09

Shukla, J., M.J. Mehta and A. Kumar, 2018. Effect of ionic liquid additives on the solubility behavior and morphology of calcium sulfate dihydrate (Gypsum) in the aqueous sodium chloride system and physicochemical solution properties at $30^{\circ} \mathrm{C}$. J. Chem. Eng. Data, 63: 2743-2752.

DOI: $10.1021 /$ acs.jced.8b00093

Tong, X.H., F. Sun, B. Zhou and S.F. Xue, 2015. Investigation on stress change and rock activation induced by water injection. Zhongguo Shiyou Daxue Xuebao (Ziran Kexue Ban)/J. China Univ. Petroleum, 39: 116-121.

DOI: $10.3969 /$ j.issn.1673-5005.2015.01.017

Wang, B.H., Y.T. Liang and M. Yuan, 2019a. Water transport system optimisation in oilfields: Environmental and economic benefits. J. Cleaner Produc.

Wang, L., H. Zhang, X.D. Peng, P.R. Wang and N. Zhao et al., 2019b. Water-sensitive damage mechanism and the injection water source optimization of low permeability sandy conglomerate reservoirs. Shiyou Kantan Yu Kaifa/Petroleum Explorat. Dev., 46: 1148-1158. DOI: 10.1016/S1876-3804(19)60275-2
Wu, J.Z., Y.Z. Liu, L. Wei, K.Y. Wu and Q.X. Lin et $a l ., 2010$. Scale inhibition in injection water with magnetic treatment in Xifeng Oilfield. Shiyou Kantan Yu Kaifa/Petroleum Explorat. Dev., 37: 490-493.

Yang, Z.M., Y.Z. Zhang, M.Q. Hao, X.G. Liu and W.W. Shan, 2006. Comprehensive evaluation of reservoir in low-permeability oilfields. Shiyou Xuebao/Acta Petrolei Sinica, 27: 64-67.

Yin, F., Y. Deng, Y.M. He, D.L. Gao and B. Hou, 2018. Mechanical behavior of casing crossing slip formation in water flooding oilfields. J. Petroleum Sci. Eng., 167: 796-802.

Yousef, A.A., S.H. Al-Saleh, A. Al-Kaabi and M.S. AlJawfi, 2011. Laboratory investigation of the impact of injection-water salinity and ionic content on oil recovery from carbonate reservoirs. SPE Reservoir Evaluation Eng., 14: 578-593.

DOI: $10.2118 / 137634-p a$

Yu, T., C.T. Qu, D.D. Fan and R.J. Xu, 2018. Effects of bentonite activation methods on chitosan loading capacity. Bull. Chem. React. Eng. Catalysis, 13: 14-23. DOI: $10.9767 /$ bcrec.13.1.1040.14-23

Yuan, S.Y. and Q. Wang, 2018. New progress and prospect of oilfields development technologies in China. Shiyou Kantan Yu Kaifa/Petroleum Exp. Dev., 45: 657-668. DOI: 10.11698/PED.2018.04.11 